Check for updates

Cite this: RSC Adv., 2019, 9, 33195

Received 18th July 2019

Accepted 5th October 2019

DOI: 10.1039/c9ra05547a

rsc.li/rsc-advances

\section{Unveiling the effect of 11-MUA coating on biocompatibility and catalytic activity of a gold- core cerium oxide-shell-based nanozyme $\uparrow$}

\begin{abstract}
Vidhi Jain, ${ }^{a}$ Stuti Bhagat, ${ }^{a}$ Mandeep Singh, ${ }^{\text {b Vipul Bansal (D) }}{ }^{\text {b }}$ and Sanjay Singh (D) *a
The biocompatibility and catalytic activity of nanomaterials exhibiting biological enzyme-like functions (nanozymes) are controlled by shape, size, composition, and surface capping molecules. Although synthesis of multifunctional nanozymes for multiple applications has shown tremendous attraction among researchers worldwide, often their biocompatibility is compromised. In this work, we report the replacement of CTAB by 11-MUA from the surface of a Au-core $\mathrm{CeO}_{2}$-shell NP-based nanozyme studied for exhibiting multiple enzyme-like activities such as peroxidase, catalase, and superoxide dismutase. We compared the biocompatibility and enzyme-like activities of CTAB coated $\mathrm{Au}$-core $\mathrm{CeO}_{2}$-shell NPs (CSNPs) before and after 11-MUA coating. The catalytic reaction mechanism of peroxidase-like activity of CTAB coated CSNPs was found to be the "Random $\mathrm{Bi}-\mathrm{Bi}$ ", which also remained unaltered after removal of surface CTAB with 11-MUA. The other kinetic parameters, $K_{m}$ and $V_{\max }$ values, of 11-MUA coated CSNPs were found to be comparable to the CTAB coated NPs.
\end{abstract}

\section{Introduction}

Last decade witnessed a surge in the area of nanozyme research due to the significant developments in the synthesis, characterization and surface modification of nanomaterials. Nanozymes are found to mimic typical biological enzyme-like reactions thus, commonly mimicking the catalytic activities of oxidases, peroxidases, superoxide dismutases, and catalases. ${ }^{1-5}$ A recent report has shown that the nanozyme mimicry is extendable beyond oxidoreductases to other enzyme classes such as hydrolases, now allowing mimicry of, for instance, lipase, esterase, galactosidase and phosphatase activities. ${ }^{6}$ Nanozymes have also been considered as next-generation synthetic enzymes because of their low synthesis cost, high reactivity due to the large surface area, and good robustness under extreme conditions. ${ }^{7}$ Utilizing the exceptional catalytic performance of nanozymes several biomedical applications have been recently realized such as immunoassays, biomolecule sensing, magnetic separation, cancer cell phenotyping, cell receptor profiling, microbial control, pro-drug activation and protection of healthy cells from deleterious reactive oxygen species. ${ }^{6,8-10}$ Gold (Au), iron oxide, and cerium oxide nanoparticles (NPs) are some of the major nanomaterials studied for exhibiting

${ }^{a}$ Division of Biological and Life Sciences, School of Arts and Sciences, Ahmedabad University, Central Campus, Ahmedabad-380009, Gujarat, India. E-mail: sanjay. singh@ahduni.edu.in; Tel: +91-079-61911270

${ }^{b}$ Ian Potter NanoBioSensing Facility, NanoBiotechnology Research Laboratory, School of Science, RMIT University, Melbourne, VIC, 3000, Australia

$\dagger$ Electronic supplementary information (ESI) available. See DOI: 10.1039/c9ra05547a enzyme mimicking activities. ${ }^{\mathbf{1 1 - 1 5}}$ In 2006, Gao et al. first reported the use of magnetite NPs for showing the intrinsic peroxidase enzyme-like activities and utilized them for developing an immunoassay where antibody-modified NPs provided multiple functions such as capture, separation, and detection. ${ }^{16}$ The magnetite NPs used in this study were coated with citrate, however, when replaced with high molecular weight dextran or polyethylene glycol (PEG) the peroxidase activity was significantly reduced. Self and coworkers first reported SOD and catalase mimetic activity in cerium oxide $\left(\mathrm{CeO}_{2}\right)$ NPs. ${ }^{17,18}$ Unlike magnetite NPs, the nanozyme activity of $\mathrm{CeO}_{2}$ NPs was reported to be unaltered when coated with PEG or dextran. ${ }^{1920}$ Recently, AuNPs have also been reported for exhibiting peroxidase enzyme-like activities due to the unique physicochemical and optical properties. ${ }^{21,22}$ Due to the easy synthesis methods and well-known surface properties, AuNPs are well explored for shape, size, and surface capping molecule dependent peroxidase-like activity. ${ }^{22-26}$ Wang et al. have compared the peroxidase-like activity of amino-modified, citrate-capped, and unmodified AuNPs and the catalytic activity was studied by oxidation of two peroxidase substrates, 3,3',5,5'-tetramethylbenzidine (TMB) and 2,2'-azino-bis(3-ethylbenzothiazoline-6-sulfonic acid)diammonium salt (ABTS). ${ }^{27}$ Their results suggest that the charge characteristics of the peroxidase activity mimicking AuNPs as well as the choice of substrate both play a significant role in the catalytic reactions. Subsequently, Shah et al. investigated the role of surface charge and capping molecule towards the peroxidaselike activity of AuNPs. ${ }^{23}$ Authors varied the charge on AuNPs surface by grafting PEG, citrate or CTAB and investigated the peroxidase-like activity. It was observed that the citrate coated AuNPs showed better activity when positively charged peroxidase 
substrate such as TMB was used, which was assumed due to the electrostatic attraction between negatively charged citrate coated AuNPs and positively charged TMB. Therefore, the same extent of enhancement was not observed when negatively charged peroxidase substrate such as ABTS was used. Therefore, when PEGcoated AuNPs (uncharged) was used with both positively and negatively charged peroxidase substrate similar peroxidase activity was observed. Although there have been several reports over the effect of surface modification of nanozymes and their effect on their catalytic activity, more such efforts are imperative to accurately modulate the activity of nanozymes.

In this context, investigating the effect of surface modification on multi-functional nanozymes is far more imperative because these nanozymes might lose some of their catalytic activities during ligand binding or exchange. In the case of SOD mimetic $\mathrm{CeO}_{2}$ NPs, it has been reported that binding of phosphate groups over NP surface leads to the loss of catalytic activity. ${ }^{28}$ Certain multifunctional nanozymes undergo selective inhibition of a particular type of activity leaving other catalytic activity unaffected. Dhall et al. have shown that $\mathrm{CeO}_{2} \mathrm{NPs}$ with high +4 cerium oxidative state exhibit two catalytic performances, catalase, and phosphatase enzyme-like activities. ${ }^{29}$ Tungstate and molybdate-based ligands selectively inhibited the phosphatase-like activity without altering the oxidation state of surface cerium atoms and concomitantly the catalaselike activity was also unaffected. These observations suggest that the catalytic activities of nanozymes can also be controlled by utilizing the binding chemistry of ligands over the nanozyme surface. Reversible regulation of catalytic activity of nanozymes is another attractive regime, which offers a regulatory mechanism to control the catalytic activity. ${ }^{30}$

Multienzyme complexes play an important role in orchestrating the catalysis of the key metabolic process including respiration, photosynthesis, and protein synthesis. Such examples have motivated the development of inorganic nanozymes exhibiting the multienzyme complex-like activities. Owing to the better catalytic activity of inorganic nanozymes than biological enzymes under a wide spectrum of physiological conditions, multifunctional nanozymes are expected to be a better alternative for efficiently controlling the metabolic processes. Multifunctional nanozymes require a combination of materials, which could be realized either in the form of coreshell or nanocomposite. Several such nanomaterials have been developed exhibiting biological enzyme-like activities but the majority is limited to the peroxidase, oxidase, superoxide dismutase, and catalase. ${ }^{31-33}$ Since, these multifunctional nanozymes require strict regulation of arrangement of materials, such as in core-shell or nanocomposites, they require a particular set of capping or share directing molecules, for example, use of CTAB for the synthesis of gold nanorods. Very frequently, these shape directed capping molecules are toxic to mammalian cells. Therefore, their removal is required before the realization of any biological application.

Capping molecules on NP surface dictate the quality of NPs (stability, monodispersity, and biocompatibility) by providing the typical functional groups $\left(-\mathrm{COO}^{-},-\mathrm{NH}_{3}{ }^{+},-\mathrm{CHO},-\mathrm{CONH}\right.$ etc.) and surface charge, which is extremely useful in surface modification and ligand exchange. ${ }^{34}$ Cetyltrimethylammonium bromide (CTAB), is a well-known shape-directing molecule during the synthesis of gold nanorods, however, has limited use in biological studies due to its cytotoxicity. Although there have been several attempts to remove the CTAB from the surface of the nanorods but the use of a CTAB replacement ligand, such as mercaptoundecanoic acid (11-MUA), has shown excellent results. He et al. reported the use of 11-MUA (in presence of sodium borohydride) as a simple, one-pot method to completely remove the CTAB from gold nanorods surface. ${ }^{24}$ Further, 11MUA coating offers biocompatibility to gold nanorods without damaging the shape and size of the rods. In this study, we report the successful replacement of CTAB with 11-MUA from $\mathrm{Au}$ core- $\mathrm{CeO}_{2}$ shell nanoparticles (CSNPs). Due to the strong affinity of the thiol groups with gold surface, we observed that the shell layer of $\mathrm{CeO}_{2}$ was also replaced, which lead to the compromised SOD and catalase enzyme-like activities of this nanozyme, while peroxidase activity was unaffected. The peroxidase-like activity was found to follow the "Random Sequential" mechanism of bimolecular chemical kinetics, which was same for CTAB as well as 11-MUA coated NPs. The biocompatibility study revealed that 11-MUA coated NPs are nontoxic to human liver cells, whereas CTAB coated CSNPs showed extreme toxicity. The detailed investigation suggested that CTAB coated CSNPs cause generation of free radicals leading to cytotoxicity, whereas 11-MUA coated NPs did not elicit such harmful events.

\section{Materials and methods}

\subsection{Materials}

11-MUA, catalase, cerium(III) nitrate hexahydrate $\left(\mathrm{Ce}\left(\mathrm{NO}_{3}\right)_{3}\right.$ $\left.\cdot 6 \mathrm{H}_{2} \mathrm{O}\right)$, xanthine oxidase, ferri-cytochrome-C, 2',7'-dichlorodihydrofluorescein diacetate (DCFDA) and TMB were obtained from Sigma-Aldrich (St. Louis, MO USA). Hydrogen peroxide $\left(\mathrm{H}_{2} \mathrm{O}_{2}\right)$, sodium borohydride $\left(\mathrm{NaBH}_{4}\right)$ and chloroauric acid $\left(\mathrm{HAuCl}_{4} \cdot 3 \mathrm{H}_{2} \mathrm{O}\right.$ ) were acquired from SD fine chemicals (Mumbai, India). CTAB, tri-sodium citrate dehydrate, hypoxanthine, minimum essential medium eagle media (MEM), ethylenediaminetetraacetic acid (EDTA), Tris hydrochloride, phosphate buffer saline (PBS), dimethyl sulfoxide (DMSO), potassium bromide $(\mathrm{KBr})$, diethylene triamine pentaacetic acid (DTPA), citric acid monohydrate, 3-(4,5-dimethylthiazol-2-yl)2,5-diphenyltetrazolium (MTT), 2-(4-amidinophenyl)-6indolecarbamidine dihydrochloride (DAPI) and antibiotic antimycotic solution were acquired from Hi-media Pvt. Ltd. (Mumbai, India) anti-fade was obtained from Life Technologies (California, USA). $\mathrm{NH}_{4} \mathrm{OH}$ (ammonium solution) was obtained from Rankem (New Delhi, India). Fetal bovine serum (FBS) was acquired from Gibco (Life Technologies Pvt. Ltd. India).

\subsection{Experimental methods}

2.2.1 Synthesis of Au seed. Au seed was synthesized by the method described by Ye et al. ${ }^{35}$ with slight modifications. In brief, a solution of $5 \mathrm{~mL} \mathrm{HAuCl}_{4} \cdot 3 \mathrm{H}_{2} \mathrm{O}(10 \mathrm{mM})$ was mixed with $0.5 \mathrm{~mL}$ CTAB (0.2 mM). This mixture was stirred for $10 \mathrm{~min}$ and 
then reduced by adding $0.6 \mathrm{~mL}$ of $0.1 \mathrm{M} \mathrm{NaBH}_{4}$. After adding reducing agent the colloidal suspension of gold became brown in color. Gold NPs (AuNPs) became red after overnight incubation at room temperature. The Au seed was aged for $96 \mathrm{~h}$ and then used for CSNPs synthesis.

2.2.2 Synthesis of NPs. Au core $\mathrm{CeO}_{2}$ shell NPs was synthesized by the method described Li, Benxia et al. ${ }^{36}$ and our group. ${ }^{37}$ In brief, $0.8 \mathrm{~mL}$ as prepared CTAB coated Au seed was mixed with $7.2 \mathrm{~mL} \mathrm{CTAB}(0.025 \mathrm{M})$ solution and $0.8 \mathrm{~mL}$ EDTA$\mathrm{NH}_{3}$ solution. Next, $0.6 \mathrm{mM} \mathrm{Ce}\left(\mathrm{NO}_{3}\right) \cdot 6 \mathrm{H}_{2} \mathrm{O}$ solution was added and made the final volume of colloidal suspension of about 10 $\mathrm{mL}$. This solution was mixed repeatedly for $1 \mathrm{~min}$ and subsequently kept in a hot air oven at $90{ }^{\circ} \mathrm{C}$ for $5 \mathrm{~h}$. The so synthesized CSNPs were centrifuged for $5 \mathrm{~min}$ at $10000 \mathrm{rpm}$. The pellet was re-dispersed into $100 \mu \mathrm{L}$ Milli-Q water for further use.

2.2.3 Surface modification of NPs. CTAB from the CSNPS was replaced by 11-MUA. About $1 \mathrm{~mL}$ suspension of CSNPs was centrifuged at $10000 \mathrm{rpm}$ for $5 \mathrm{~min}$ and the pellet was resuspended in $1 \mathrm{~mL}$ 11-MUA solution (20 mM) and allowed to mix overnight. Next day, this mixture was centrifuged for $10 \mathrm{~min}$ at $4000 \mathrm{rpm}$ and the pellet was re-dispersed in Milli-Q water for further use.

2.2.4 Characterization of NPs. UV-Vis absorbance spectra of $\mathrm{Au}$ seeds, $\mathrm{CeO}_{2}$ NPs, and CSNPs, before and after 11-MUA coating, was taken by using multiwell plate reader, Synergy HT spectrophotometer, BioTek. Zeta potential of NPs was obtained using DLS (Dynamic Light Scattering) with Zeta sizer nano, Malvern instruments. The size and shape of CSNPs before and after 11-MUA coating was studied using Transmission Electron Microscope (TEM) by JEM 1400 plus, JEOL. High-resolution TEM (HRTEM) studies accompanied with EDX chemical mapping in STEM mode were performed on a JEOL $2100 \mathrm{~F}$ microscope operating at $200 \mathrm{kV}$ accelerating voltage. The suspension of AuNPs, $\mathrm{CeO}_{2}$ NPs and CSNPs, before and after 11MUA coating, was loaded on copper grid and dried overnight at room temperature. Elemental analysis of CSNPs before and after 11-MUA coating was done by using SEM (Scanning electron microscope) equipped with EDX (Energy dispersive X-ray spectroscopy) (JEOL, JSM 6010LA). The presence of CTAB and 11-MUA on CSNPs was also checked by using FTIR (Fourier transformed infrared) spectroscopy. About $100 \mu \mathrm{L}$ of samples were crushed with $\mathrm{KBr}$ and dried under IR lamp for $3 \mathrm{~h}$. For control, same volume of Milli-Q water was mixed with $\mathrm{KBr}$. The samples were analyzed by using attenuated total reflection mode in Spectrum Two (L160000A, PerkinElmer) between the range of $400-4000 \mathrm{~cm}^{-1}$.

2.2.5 Cell line cultivation. Normal human liver cell line (WRL-68) was purchased from NCCS (National Centre for Cell Sciences), Pune, India. WRL-68 cells were maintained in MEM medium containing $10 \%$ FBS and $1 \%$ antibiotic antimycotic solution at $37{ }^{\circ} \mathrm{C}$ with $5 \% \mathrm{CO}_{2}$ humidified environment.

2.2.6 MTT assay. About $1 \times 10^{4}$ cells per well were seeded in a 96-well plate and incubated overnight for adherence. Different concentrations $\left(10-100 \mu \mathrm{g} \mathrm{mL}^{-1}\right)$ of CTAB and 11MUA coated NPs were incubated with cells for $24 \mathrm{~h}$ followed by addition of $0.5 \mathrm{mg} \mathrm{mL} \mathrm{mL}^{-1}$ MT dye. The formazan crystals formed due to reduction of MTT dye were then solubilized in
$100 \mu \mathrm{L}$ of DMSO. The dissolved formazan was measured by recording absorbance at $590 \mathrm{~nm}$ in a multi-well plate reader in (BioTek, Synergy HT spectrophotometer).

2.2.7 Reactive oxygen species detection. About $5 \times 10^{4}$ cells were seeded per well on coverslips placed in a 6 well plate. Seeded cells were incubated overnight for adherence. Afterwards, cells were treated with 10,20 , and $40 \mu \mathrm{g} \mathrm{mL}{ }^{-1}$ of CSNPs before and after 11-MUA coating for $24 \mathrm{~h}$ followed by $30 \mathrm{~min}$ incubation in $20 \mu \mathrm{M}$ DCFDA. Subsequently, cells were fixed with ice chilled methanol for $10 \mathrm{~min}$, washed with PBS and stained by using $2.5 \mu \mathrm{g} \mathrm{mL} \mathrm{m}^{-1}$ DAPI. Coverslips were placed on to the glass-slide with anti-fade mounting media and stored at $4{ }^{\circ} \mathrm{C}$ until use. The slides were imaged under a fluorescence microscope (DM 2500, Leica).

2.2.8 Preparation of buffers. A $100 \mathrm{~mL}(0.1 \mathrm{M})$ of citrate buffer ( $\mathrm{pH}-4.0$ ) was prepared by mixing $0.1 \mathrm{M}$ citric acid monohydrate solution and $0.1 \mathrm{M}$ trisodium citrate solution in 59 : 41 ratio. This buffer was used to maintain the $\mathrm{pH}$ of the reaction medium during the peroxidase-like activity estimation of NPs. 1 M Tris buffer ( $\mathrm{pH}$ - 7.0) was prepared by using Trisbase which was used for the analysis of catalase-like activity of NPs. $1 \mathrm{M}$ Tris buffer was further diluted to prepare $10 \mathrm{mM}$ Tris buffer for analysis of SOD-like activity. The $\mathrm{pH}$ of these buffers was maintained by addition of $\mathrm{NaOH}$ or $\mathrm{HCl}$.

2.2.9 Peroxidase-like activity of NPs. $1 \mathrm{mM}$ TMB was used as chromogenic substrate to measure peroxidase-like activity of the different concentration of NPs before and after 11-MUA coating. Addition of $\mathrm{H}_{2} \mathrm{O}_{2}(2 \mathrm{M})$ converted the reduced TMB into oxidized TMB which gives blue colored product. The peroxidase-like activity was buffered with $0.1 \mathrm{M}$ citrate buffer at pH 4.0 in a reaction volume of $500 \mu \mathrm{L}$. Increase in the absorbance was recorded for $20 \mathrm{~min}$ at $652 \mathrm{~nm}$.

2.2.10 Enzyme-like reaction kinetics. Kinetic analysis of the peroxidase-like activity was performed using $40 \mu \mathrm{g} \mathrm{mL}$ concentration of NPs at $37{ }^{\circ} \mathrm{C}$. For TMB dependent kinetics, concentration of TMB was varied from $0.05 \mathrm{mM}$ to $5 \mathrm{mM}$ at constant concentration of $\mathrm{H}_{2} \mathrm{O}_{2}$. Different concentration of 0.5 , 1, and $2 \mathrm{M} \mathrm{H}_{2} \mathrm{O}_{2}$ used for calculation of kinetic parameters. While for $\mathrm{H}_{2} \mathrm{O}_{2}$ dependent kinetics, concentration of $\mathrm{H}_{2} \mathrm{O}_{2}$ was varied from $0.5 \mathrm{M}$ to $3 \mathrm{M}$ at constant TMB concentration $(0.5,1$, and $2 \mathrm{mM}$ ). $0.1 \mathrm{M}$ citrate buffer ( $\mathrm{pH} 4)$ was used for regulating $\mathrm{pH}$ of the reaction. The total reaction volume of $500 \mu \mathrm{L}$ was maintained. Absorbance was recorded at $652 \mathrm{~nm}$ in kinetic mode at interval of $1 \mathrm{~min}$ for $40 \mathrm{~min}$. The kinetic parameters Michaelis constant $\left(K_{\mathrm{m}}\right)$ and maximal reaction velocity $\left(V_{\max }\right)$ were calculated by using Lineweaver-Burk plot,

$$
\frac{1}{v}=\frac{K_{\mathrm{m}}}{V_{\max }}\left(\frac{1}{[\mathrm{~S}]}+\frac{1}{K_{\mathrm{m}}}\right)
$$

where, $[\mathrm{S}]=$ substrate concentration and $v=$ initial velocity.

2.2.11 SOD-like activity of NPs. SOD activity was performed as described by Korsvik et al. ${ }^{17}$ In brief, the SOD-like activity of CTAB and 11-MUA coated CSNPs was tested using ferricytochrome $\mathrm{C}$ which gets reduced in the presence of superoxide radical $\left(\mathrm{O}_{2}{ }^{-}\right)$and give orange color product. Superoxide radicals were produced by reaction of xanthine oxidase and hypoxanthine. Catalase enzyme was added for removing $\mathrm{H}_{2} \mathrm{O}_{2}$ 
from the reaction system. 50, 75, 100 and $150 \mu \mathrm{g} \mathrm{mL}^{-1}$ concentrations of CSNPs before and after 11-MUA coating were taken to measure SOD mimetic activity. Reaction was performed in a 96 well plate with total volume of $100 \mu \mathrm{L} .10 \mathrm{mM}$ Tris buffer of pH-6.8 was used for buffering the reaction and absorbance of the reaction mixture was monitored for $20 \mathrm{~min}$ at $550 \mathrm{~nm}$.

2.2.12 Catalase-like activity of NPs. Catalase activity was performed, as described by Pirmohamed et al. ${ }^{18}$ Catalase enzyme-like activity of CSNPs before and after 11-MUA coating was measured using UV-Vis spectrophotometer by monitoring the decrease in absorbance of $\mathrm{H}_{2} \mathrm{O}_{2}$ at $240 \mathrm{~nm}$. About $50 \mathrm{mM}$ Tris buffer ( $\mathrm{pH}$ 7.0) was used in $1 \mathrm{~mL}$ reaction volume containing DTPA (1 mM), $\mathrm{H}_{2} \mathrm{O}_{2}(5 \mathrm{mM})$ and 50 and $100 \mu \mathrm{g} \mathrm{mL}$ concentrations of CSNPs (before and after 11-MUA coating) to measure catalase-like activity.

\section{Results and discussion}

\subsection{Synthesis and characterization of CTAB and 11-MUA coated $\mathrm{Au}$ core- $\mathrm{CeO}_{2}$ shell NPs}

The typical synthesis method of spherical AuNPs, CSNPs, and $\mathrm{CeO}_{2}$ NPs was performed following the protocol reported by our group $^{37}$ and others, ${ }^{36}$ with slight modification. The monometallic AuNPs were synthesized using CTAB (as capping molecules) and sodium borohydride (as reducing agent), which results in the formation of roughly monodispersed AuNPs protected with a monolayer of CTAB. The so produced dark brownish-red color colloidal suspension of AuNPs was used as a core to decorate the surface with $\mathrm{CeO}_{2} \mathrm{NPs}$ in the form of a thick shell. The CTAB coated spherical AuNPs showed a characteristic plasmon absorbance at $\sim 525 \mathrm{~nm}$ (Fig. 1A, black curve). Subsequently, a thick shell of $\mathrm{CeO}_{2}$ was formed over AuNPs core by mixing of $\mathrm{Ce}\left(\mathrm{NO}_{3}\right)_{3}$, EDTA and ammonia. This reaction lead to the formation of anionic Ce(III)-EDTA complex, which is readily adsorbed electrostatically on the surface of cationic CTAB coated AuNPs in the suspension. The chelating activity of EDTA prevents the fast hydrolysis of Ce(III) by ammonia. Next, the above mixture was incubated at $90{ }^{\circ} \mathrm{C}$ to allow slow hydrolysis of Ce(III) from Ce(III)-EDTA complex followed by condensation on the surface of AuNPs core thus leading to the formation of CSNPs.

The formation of $\mathrm{CeO}_{2}$ shell on $\mathrm{Au}$ core was further evidenced by following the plasmon absorbance, which shows a clear shift in the absorption of AuNPs in CSNPs by $\sim 10 \mathrm{~nm}$ (Fig. 1A, red curve). Although the CTAB coated CSNPs are well dispersed and form a stable colloidal suspension, however, their biological applications are largely limited. Therefore, we attempted to replace the CTAB coating by using 11-MUA, a thiol containing molecule. Gold is well known to display strong affinity for thiol groups and therefore several strategies of surface modification of AuNPs has been developed exploiting thiol and AuNPs chemistry. ${ }^{38}$ In our experiments, when CTAB coated CSNPs were exposed to 11-MUA, a significant bathochromic shift of $\sim 17 \mathrm{~nm}$ of plasmon absorbance of AuNPs was observed (Fig. 1A, green curve). This shift in plasmon absorbance suggests the possible replacement of CTAB with 11-MUA
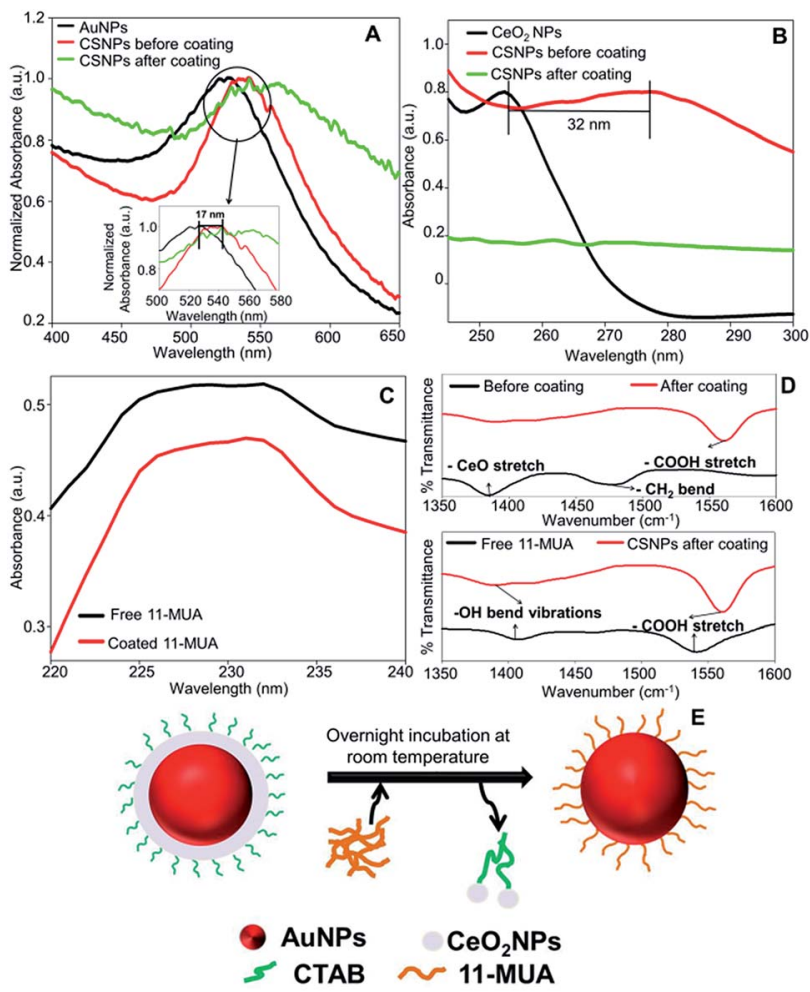

Fig. 1 UV-Vis spectra of AuNPs, $\mathrm{Au} / \mathrm{CeO}_{2} \mathrm{CSNPs}$ before and after 11MUA coating (A). Before 11-MUA coating absorbance shifts for AuNPs and $\mathrm{CeO}_{2} \mathrm{NPs}$. Absence of absorbance peak for $\mathrm{CeO}_{2} \mathrm{NPs}$ after 11MUA coating (B). Signature peak for 11-MUA which can also be seen for $\mathrm{Au} / \mathrm{CeO}_{2}$ CSNPs post surface functionalization (C). FTIR Spectra for 11MUA, $\mathrm{Au} / \mathrm{CeO}_{2}$ CSNPs before 11-MUA coating and after 11-MUA coating (D). Schematic diagram showing the loss of $\mathrm{CeO}_{2}$ shell after replacement of CTAB with 11-MUA (E).

in CSNPs. Next, we also studied the change in the absorbance pattern of $\mathrm{CeO}_{2}$ NPs present as shell in CSNPs. $\mathrm{CeO}_{2}$ (III) NPs dispersed in water display a typical absorbance at $\sim 250 \mathrm{~nm}$ (Fig. 1B, black curve), however, when present as shell in CTAB coated CSNPs, a bathochromic shift of $\sim 32 \mathrm{~nm}$ was observed (Fig. 1B, red curve). This observation also suggests the possible formation of $\mathrm{CeO}_{2}$ (III) NPs shell on AuNPs core. Subsequently, the absorbance of $\mathrm{CeO}_{2}$ NPs was also followed in the 11-MUA coated CSNPs. Interestingly, the typical absorbance of $\mathrm{CeO}_{2} \mathrm{NPs}$ was found absent in 11-MUA coated CSNPs (Fig. 1B, green curve). Although we performed a detailed characterization to investigate this observation (vide infra), we assume that due to the strong affinity of thiol group from 11-MUA with AuNPs, the $\mathrm{CeO}_{2}$ (from a shell) is also removed along with the CTAB.

Further, we also investigated the presence of 11-MUA on CSNPs and the results are displayed in Fig. 1C. Free solution of 11-MUA shows a typical broad absorbance pattern ranging between 225-235 nm (Fig. 1C, black curve). This broad absorbance was also found present in CSNPs sample in which CTAB was replaced with 11-MUA (Fig. 1C, red curve). Next, we also studied the status of CTAB and $\mathrm{CeO}_{2}$ in CSNPs after 11-MUA coating by FTIR (Fig. 1D). The CSNPs clearly show a characteristic "Ce-O" stretching band at $\sim 1390 \mathrm{~cm}^{-1}$ suggesting the 
presence of $\mathrm{CeO}_{2}$ in the sample (Fig. 1D, top panel, black curve). However, the similar transmission pattern was absent in the 11MUA coated CSNPs sample (Fig. 1D, top panel, red curve). This observation suggests that $\mathrm{CeO}_{2}$ is removed from 11-MUA coated CSNPs, supporting our conclusion from UV-Vis absorbance data (vide supra). Further, transmission signal for " $\mathrm{H}-\mathrm{C}-\mathrm{H}$ " bending vibration was also observed at $\sim 1478 \mathrm{~cm}^{-1}$ in CSNPs, which could be due to the presence of CTAB (Fig. 1D, top panel, black curve). As expected, CSNPs coated with 11-MUA did not show any transmission peak in this region suggesting the successful removal of CTAB (Fig. 1D, top panel, red curve). Interestingly, 11-MUA coated CSNPs showed a new transmission signal at $\sim 1562 \mathrm{~cm}^{-1}$, which could be ascribed to the "-COOH" group present in 11-MUA (Fig. 1D, top panel, red curve). Further, we also investigated the presence of 11-MUA over CSNPs with free 11-MUA molecules. The FTIR data show the presence of characteristic " $\mathrm{O}-\mathrm{H}$ " bending and "-COOH" stretching vibrations in pure 11-MUA sample (Fig. 1D, bottom panel, black curve). As expected, both of these signature transmission signals are also found present in 11-MUA coated CSNPs (Fig. 1D, bottom panel, red curve). The transmittance signals are shifted towards higher wavenumber, which could be due to the immobilization of 11MUA molecules on CSNPs surface. Therefore, this and our other observations suggest that CTAB coating is successfully replaced by 11-MUA from the surface of CSNPs, however, in this process, the $\mathrm{CeO}_{2}$ shell is also removed (Fig. 1E). Next, we also followed the change in zeta potential value of CTAB coated AuNPs $(+32.23$ $\pm 2.01 \mathrm{mV}), \mathrm{CeO}_{2} \mathrm{NPs}(+31.27 \pm 1.20 \mathrm{mV})$, and CSNPs before $(+21.7 \pm 1.30 \mathrm{mV})$, and after $(-37.2 \pm 0.78 \mathrm{mV})$ 11-MUA coating (Table 1). The positive zeta potential on CSNPs suggests the presence of $\mathrm{CTAB}$, however, negative zeta potential value indicates the presence of 11-MUA on the surface of CSNPs. This observation further suggests the replacement of CTAB from CSNPs by 11-MUA. Further, the high zeta potential values suggest that the particles form a stable colloidal suspension even after the replacement of surface CTAB with 11-MUA. To investigate the shape, size, and morphology of CTAB coated AuNPs, $\mathrm{CeO}_{2}$ NPs, and CSNPs (before and after 11-MUA coating) high resolution transmission electron microscope (HRTEM) imaging was performed. Typical core-shell structures are evident from TEM images (Fig. 2A); where the electronically dense (due to high atomic number) structure suggest the presence of AuNPs, whereas the amorphous layer of shell around AuNPs represent the $\mathrm{CeO}_{2} \mathrm{NPs}$ (Fig. 2A, inset). Although

Table 1 Zeta potential values of CTAB coated AuNPs, $\mathrm{CeO}_{2} \mathrm{NPs}$ and CTAB coated and 11-MUA coated CSNPs was recorded by Dynamic Light Scattering measurements. Data shown as mean \pm standard deviation of triplicate samples

Nanoparticles

CTAB coated AuNPs

$\mathrm{CeO}_{2} \mathrm{NPs}$

CTAB coated CSNPs

11-MUA coated

CSNPs the thickness of the $\mathrm{CeO}_{2}$ shell is not uniform around the $\mathrm{Au}$ core, which could be due to the variation in the size of Au core. It is assumed that with a varying diameter of Au core, the extent of hydrolysis of $\mathrm{CeO}_{2}$ may also be different and thus the shell thickness. The average particle size distribution (Fig. 2A, inset) of $\mathrm{Au}$ core and $\mathrm{CeO}_{2}$ shell are calculated $\sim 12$, and $\sim 20 \mathrm{~nm}$, respectively. The TEM image of CSNPs after 11-MUA coating (Fig. 2B) showed the presence of a very thin layer of $\mathrm{CeO}_{2}$ shell around $\mathrm{Au}$ core. Further, the average particle distribution size (Fig. 2B, inset) of Au core was significantly increased to $\sim 40 \mathrm{~nm}$, whereas the average thickness of the $\mathrm{CeO}_{2}$ shell was $\sim 4 \mathrm{~nm}$. This observation confirms that in the process of replacement of CTAB with 11-MUA from CSNPs the $\mathrm{CeO}_{2}$ shell is also removed from the $\mathrm{Au}$ core surface. In order to further probe the composition of CTAB and 11-MUA coated CSNPs, we investigated them with HRTEM imaging (Fig. 2C-F). The distances measured from the lattice planes on average correspond to $\sim 0.23 \mathrm{~nm}$ (core) and $0.33 \mathrm{~nm}$ (shell) corresponding to the lattice spacings of $\mathrm{Au}$ (111) and $\mathrm{CeO}_{2}$ (111) planes, respectively. These observations clearly suggest that core and shell structures are composed of $\mathrm{Au}$ and $\mathrm{CeO}_{2}$, respectively. Interestingly, a very thin layer of shell $\mathrm{CeO}_{2}$ NPs (Fig. 2B) on AuNPs core is suggesting the loss of shell layer. The TEM images of CTAB coated

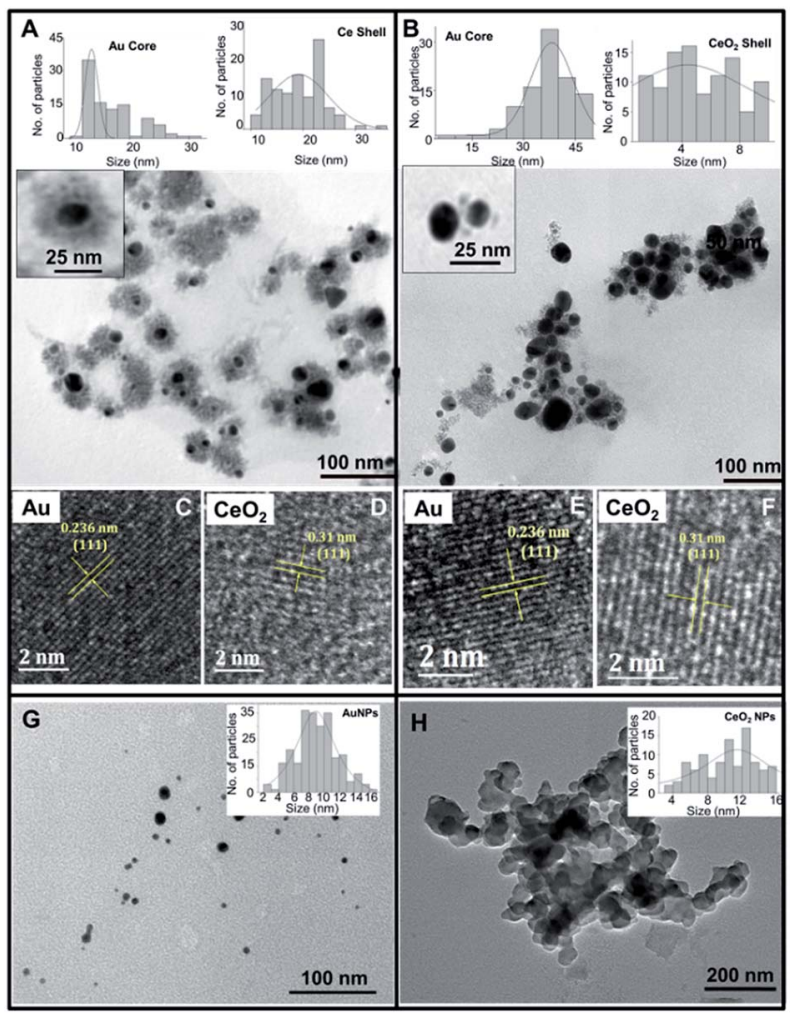

Fig. 2 Size and morphology study of CSNPs: transmission electron micrograph of CTAB coated (A), and 11-MUA coated (B) CSNPs, CTAB coated AuNPs (G), and $\mathrm{CeO}_{2}$ NPs $(\mathrm{H})$. Inset shows the average particle size distribution of respective transmission electron micrographs. Inset of $A$ and $B$ represents a high resolution transmission electron micrograph of CTAB and 11-MUA coated CSNPs, respectively. HR-TEM analysis of presence of $\mathrm{Au}\left(\mathrm{C}\right.$ and $\mathrm{E}$ ) and $\mathrm{CeO}_{2}(\mathrm{D}$ and $\mathrm{F})$ in $\mathrm{CTAB}$ and 11-MUA coated CSNPs, respectively. 
AuNPs (Fig. 2G) and $\mathrm{CeO}_{2}$ NPs (Fig. 2H) suggest that these particles are also well dispersed with the average particle size distribution of $\sim 10$ and $\sim 12 \mathrm{~nm}$, respectively. In order to confirm the loss of $\mathrm{CeO}_{2}$ shell layer from Au core, we studied the XRD pattern of CTAB and 11-MUA coated CSNPs (Fig. 1 ESI $\dagger$ ). The $2 \theta$ values for Au from CTAB coated CSNPs was observed at [33.8 (111), and 54.2 (200)], whereas for $\mathrm{CeO}_{2}$ [45.7 (311), and 50.0 (220)] suggesting the presence of gold and $\mathrm{CeO}_{2}$ possibly in form of a core shell, respectively. Interestingly after 11-MUA coating more lattice planes of $\mathrm{Au}$ are seen at [38.7 (111), 44.7 (200), 64.7 (220) and 76.6 (311)], characteristic to spherical AuNPs. This observation suggest that after removal of $\mathrm{CeO}_{2}$ shell, the surface of AuNPs are exposed and thus, producing successful characteristic diffraction patterns. Subsequently, we also investigated the composition of CSNPs, before and after 11MUA coating, by scanning electron microscope (SEM) equipped with energy dispersive analysis of X-rays (EDAX).

The elemental mapping data revealed the presence of characteristic energy level signals of "Br", "Ce", and "Au" suggesting the presence of $\mathrm{Au}$ core- $\mathrm{CeO}_{2}$ shell structure (Fig. 3A-E). Further, the 11-MUA coated CSNPs showed the presence of "S" (Fig. 3D'), and "Au", however, the signal for "Ce" was feeble, suggesting the removal of $\mathrm{CeO}_{2}$ shell during removal of CTAB (Fig. $3 \mathrm{~A}^{\prime}-\mathrm{E}^{\prime}$ ). Interestingly, a significant amount of " $\mathrm{S}$ " signal was observed, which could be ascribed to the presence of the thiol group after 11-MUA coating. Additionally, there was no signal for "Br" (Fig. 3D), after 11-MUA coating, which confirms the replacement of CTAB with 11-MUA. Thus, on the basis of above characterization data, it can be concluded that CTAB is successfully removed from the surface of CSNPs with concomitant loss of $\mathrm{CeO}_{2}$ shell as well. Therefore, in subsequent sections, 11-MUA coated CSNPs will be referred as 11-MUA coated AuNPs.

\subsection{Biocompatibility comparison of 11-MUA coated AuNPs and CTAB coated CSNPs towards human liver cells}

Core-shell NPs are reported to be applicable in several biological applications such as mimicking the activities of multienzyme complexes, sensitive detection of analytes of biological importance, multimodal imaging, and drug delivery strategies. $^{39-41}$ CTAB is a cationic surfactant, therefore, causes damage to the cell membrane. ${ }^{42,43}$ Therefore, it must be removed completely to realize any biological application of our CSNPs. Gold nanorods (GNRs) are typically synthesized in the presence of an excess of CTAB, which limits the applications of GNRs in biological applications. Leonov et al. have used polystyrenesulfonate to replace the CTAB from GNRs surface to reduce their cytotoxicity. ${ }^{43}$ Additionally, Mehtala et al. have reported the synthesis of citrate coated GNRs by first replacing CTAB with polystyrenesulfonate followed by citrate. ${ }^{44}$ Therefore, we also compared the biocompatibility of CTAB coated CSNPS and 11-MUA coated AuNPs. The biocompatibility assessment was performed by MTT assay on WRL-68 (normal human liver cells) exposed to different concentrations of CSNPs for $24 \mathrm{~h}$ (Fig. 4A). Data clearly show that $20 \mu \mathrm{g} \mathrm{mL}{ }^{-1}$ concentration of CTAB coated CSNPs induced significant death $(\sim 40 \%)$ to liver cells, whereas higher concentrations $(40,60,80$ and $100 \mu \mathrm{g}$ $\mathrm{mL}^{-1}$ ) showed further enhanced toxicity and decrease to cell viability up to $90 \%$. Interestingly, 11-MUA coated AuNPs did not show any toxicity to WRL-68 cells up to $100 \mu \mathrm{g} \mathrm{mL}$
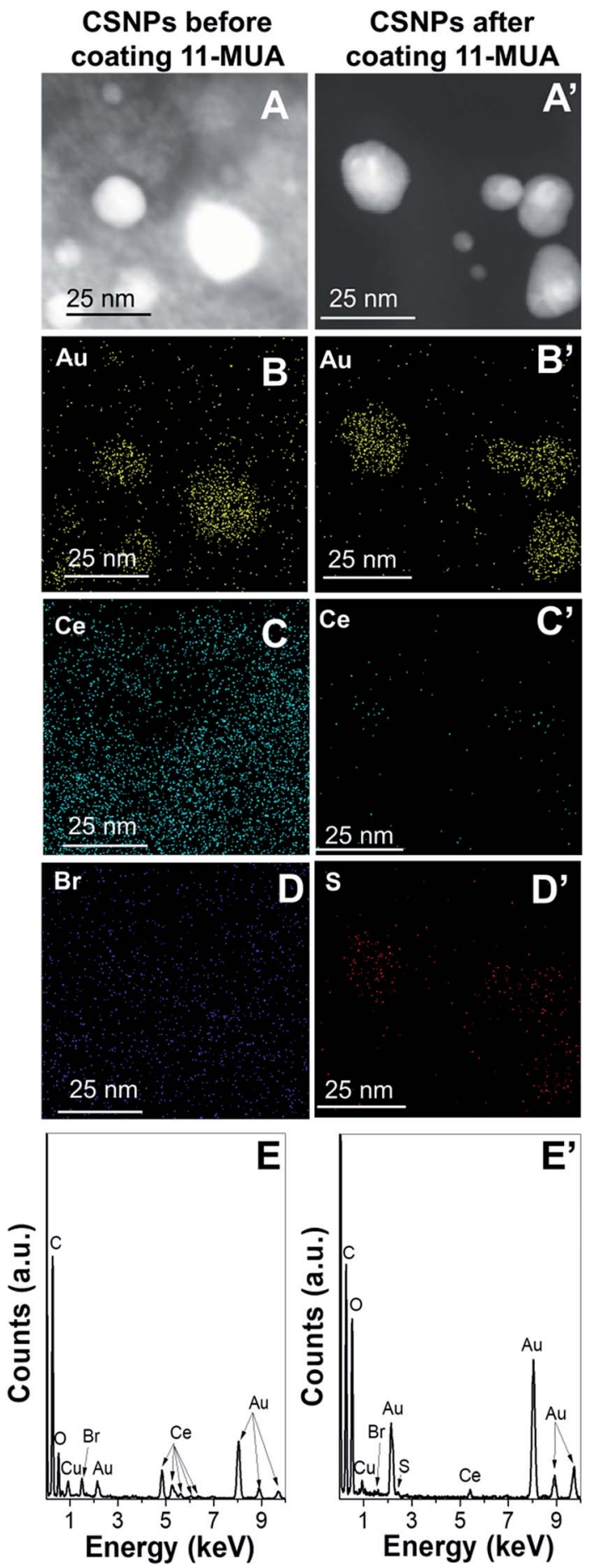

Fig. 3 Elemental mapping of before and after coating of $\mathrm{Au} / \mathrm{CeO}_{2}$ CSNPs by using Energy dispersive $X$-ray spectroscopy (EDX): scanning electron micrograph $\left(A, A^{\prime}\right)$, elemental mapping of $A u\left(B / B^{\prime}\right), C e\left(C / C^{\prime}\right)$, $\operatorname{Br}(D)$ and $S\left(D^{\prime}\right)$. E and $E^{\prime}$ show counts of elements in CSNPs before and after 11-MUA coating, respectively. 
concentration. Further, we also followed the cell morphology pattern of WRL-68 cells exposed to different concentrations of CTAB coated CSNPs (Fig. 4B-H) and 11-MUA coated AuNPs
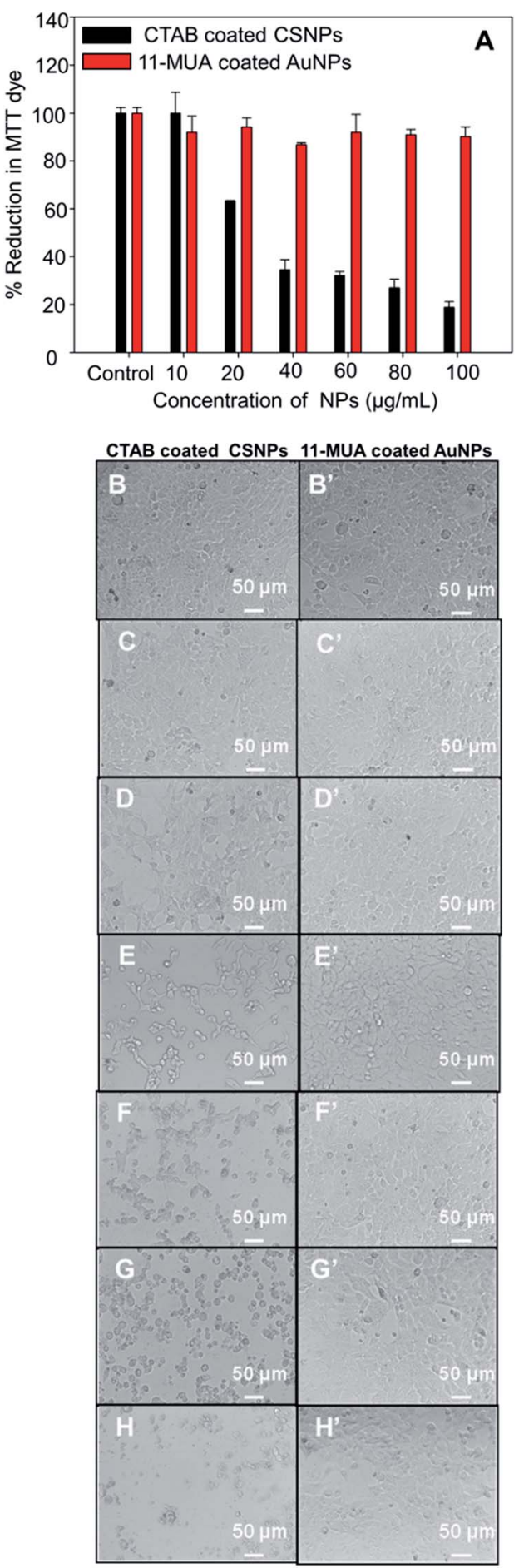

Fig. 4 Biocompatibility assessment of NPs: the \% reduction of MTT dye observed from human liver (WRL-68) cells exposed to different concentrations of CTAB coated CSNPs and 11-MUA coated AuNPs (A). The cell morphology pattern was investigated by imaging of the cells exposed to different concentrations $\left(10,20,40,60,80\right.$, and $\left.100 \mu \mathrm{g} \mathrm{mL}^{-1}\right)$ of CTAB coated CSNPs (C, D, E, F, G, and H) and 11-MUA coated AuNPs $\left(C^{\prime}, D^{\prime}, E^{\prime}\right.$, $F^{\prime}, G^{\prime}$ and $H^{\prime}$ ), respectively. $B$ and $B^{\prime}$ are untreated control. Data expressed as standard error calculated from 3 experiments.
(Fig. $4 \mathrm{~B}^{\prime}-\mathrm{H}^{\prime}$ ). Corroborating with the MTT data, $20 \mu \mathrm{g} \mathrm{mL}^{-1}$ concentration of CTAB coated CSNPs showed a significant change in the cell morphology (Fig. 4D) as well as cell number when compared with untreated control cells (Fig. 4B). Similarly, higher concentrations of CTAB coated CSNPs exposure lead to cause further deformation in the cell morphology in a concentration-dependent manner (Fig. 4E-H). Conversely, different concentrations $\left(10,20,40,60,80\right.$, and $\left.100 \mu \mathrm{g} \mathrm{mL}{ }^{-1}\right)$ of 11-MUA coated AuNPs did not induce any significant alteration of the

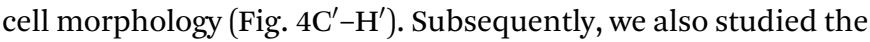
possibility of oxidative stress in WRL-68 cells due to the exposure of CTAB coated CSNPs and 11-MUA coated AuNPs (Fig. 5). Fluorescence microscopy data revealed that exposure of $5 \mu \mathrm{g}$ $\mathrm{mL}^{-1}$ of CTAB coated CSNPs did not induce oxidative stress as there was no green fluorescence observed (Fig. 5, panel B). However, exposure of higher concentrations $(10$, and $20 \mu \mathrm{g}$ $\mathrm{mL}^{-1}$ ) of CTAB coated CSNPs to WRL-68 cells induced concentration-dependent oxidative stress as bright green fluorescence signal (due to oxidized $\mathrm{H}_{2}$ DCFDA signal) can be seen (Fig. 5, panel C and D). Contrary to this, similar concentrations $\left(5,10\right.$, and $\left.20 \mu \mathrm{g} \mathrm{mL}^{-1}\right)$ of 11-MUA coated AuNPs did not induce any oxidative stress in WRL-68 cells, which is evident by no fluorescence signal from cell cytoplasm (Fig. 5, panel E, F, and

A
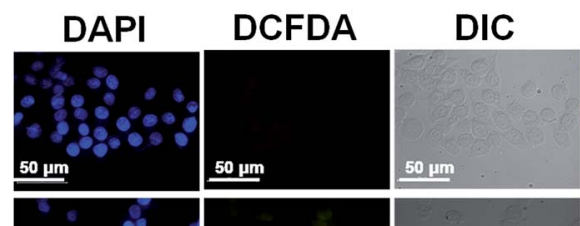

MERGE

B
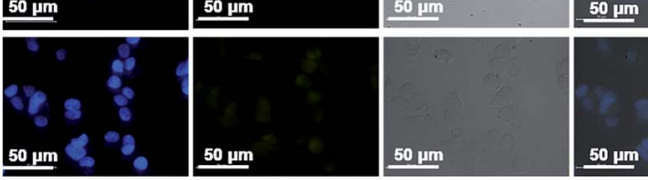

C
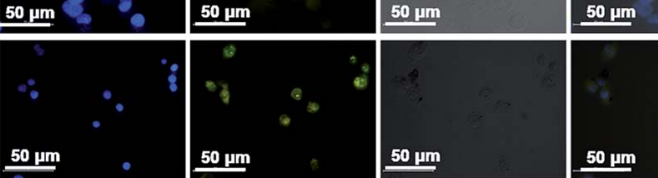

D
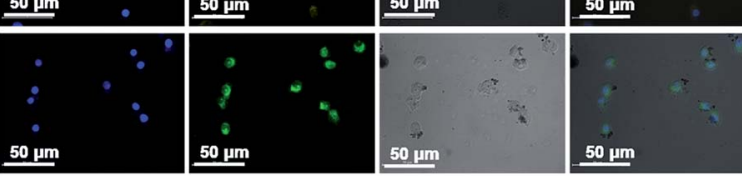

$\mathbf{E}$
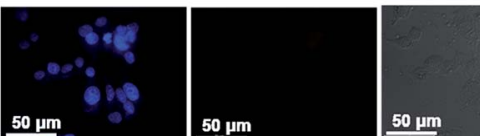

$\mathbf{F}$
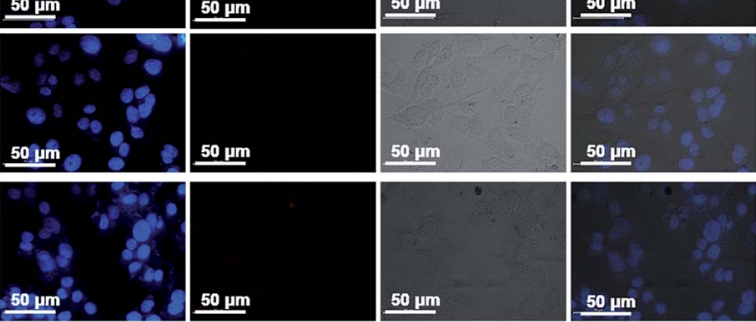

Fig. 5 Free radical levels in WRL-68 cells after CSNPs exposure: WRL68 cells were exposed to different concentrations of CTAB coated CSNPs $\left[5 \mu \mathrm{g} \mathrm{mL}^{-1}\right.$ (B), $10 \mu \mathrm{g} \mathrm{mL}^{-1}$ (C), $20 \mu \mathrm{g} \mathrm{mL}^{-1}$ (D)] and 11-MUA coated AuNPs [5 $\mu \mathrm{g} \mathrm{mL}^{-1}$ (E), $10 \mu \mathrm{g} \mathrm{mL}^{-1}$ (F), $20 \mu \mathrm{g} \mathrm{mL}{ }^{-1}$ (G)] for 24 hours followed by imaging under fluorescence microscope. 
G). These observations also suggest that CSNPs coated with CTAB induce oxidative stress in human liver cells, however, when CTAB is replaced with 11-MUA, AuNPs become biocompatible and do not prompt free radicals formation.

\subsection{Effect of 11-MUA coating on enzyme-like activities of NPs}

Recently, we have shown that CTAB coated CSNPs show multienzyme complex-like activities mimicking peroxidase, catalase, and superoxide dismutase enzyme-like activities. ${ }^{37}$ These enzyme-like activities could be controlled simply by varying the $\mathrm{pH}$ of the reaction buffer, which suggests that their "prooxidant" and "anti-oxidant" activities could be precisely controlled and therefore, used in several biomedical applications. However, the CTAB coating could cause toxicity to the mammalian cells, therefore, in order to impart biocompatibility, we replaced CTAB with 11-MUA from CSNPs surface. Further, the coating of 11-MUA may cause alteration in the catalytic activity of NPs, therefore, we also evaluated their different enzyme-like activities before and after coating with 11MUA.

3.3.1 Peroxidase-like activity. To investigate peroxidase-like activity, $100 \mu \mathrm{g} \mathrm{mL} \mathrm{m}^{-1}$ each of CTAB coated CSNPs and 11-MUA coated AuNPs were reacted with TMB, a chromophoric peroxidase substrate, in presence of hydrogen peroxidase. TMB (reduced) is a colorless substrate which produces blue-colored product (absorbance $652 \mathrm{~nm}$ ) upon oxidation. It is evident from Fig. 6A that the maximum absorbance intensity of oxidized TMB at $652 \mathrm{~nm}$ is almost similar for CTAB coated CSNPs (Fig. 6A, blue curve, inset tube 4) and 11-MUA (Fig. 6A, pink curve, inset tube 5) coated AuNPs. This observation suggests that the peroxidase-like activity of CSNPs was unaffected even after replacement of surface CTAB with 11-MUA. We also tested CTAB coated $\mathrm{CeO}_{2}$ NPs and a physical mixture of $\mathrm{CTAB}$ and $\mathrm{CeO}_{2}$ NPs for any potential peroxidase enzyme-like activity (Fig. 2 ESI $\dagger$ ). As expected, these NPs did not show any peroxidase-like activity. The control reactions of CSNPs alone (tube 1), CTAB only (tube 2), and 11-MUA only (tube 3) with $\mathrm{H}_{2} \mathrm{O}_{2}$ did not give any evolution of blue color. The reaction kinetics of the above discussed peroxidase-like activity of NPs was also followed by observing the normalized absorbance of oxidized TMB at $652 \mathrm{~nm}$ for 20 min (Fig. 6B).

Subsequently, we also studied the effect of temperature and $\mathrm{pH}$ on the peroxidase enzyme-like activity of CTAB coated CSNPs and 11-MUA coated AuNPs (Fig. 3 and 4 ESI $\dagger$ ). Results show that the NPs show maximum peroxidase activity at $\mathrm{pH} 4$, whereas about $40-50 \%$ of activity is retained even at $\mathrm{pH} 12$. Replacement of CTAB with 11-MUA did not cause any significant change in activity at different $\mathrm{pH}$. Similarly, we also studied the peroxidase-like activity of CTAB coated CSNPs and 11-MUA coated AuNPs at different temperatures (20-90 $\left.{ }^{\circ} \mathrm{C}\right)$. As clearly evident from Fig. 4 ESI, $\uparrow$ the maximum activity was seen at $\sim 40{ }^{\circ} \mathrm{C}$, however, any increase or decrease in temperature caused lower peroxidase activity. CTAB coated CSNPs showed better activity than 11-MUA coated AuNPs when exposed to similar temperatures. This could be because CSNPs are densly coated with $\mathrm{CeO}_{2}$ NPs and CTAB, whereas due to removal of
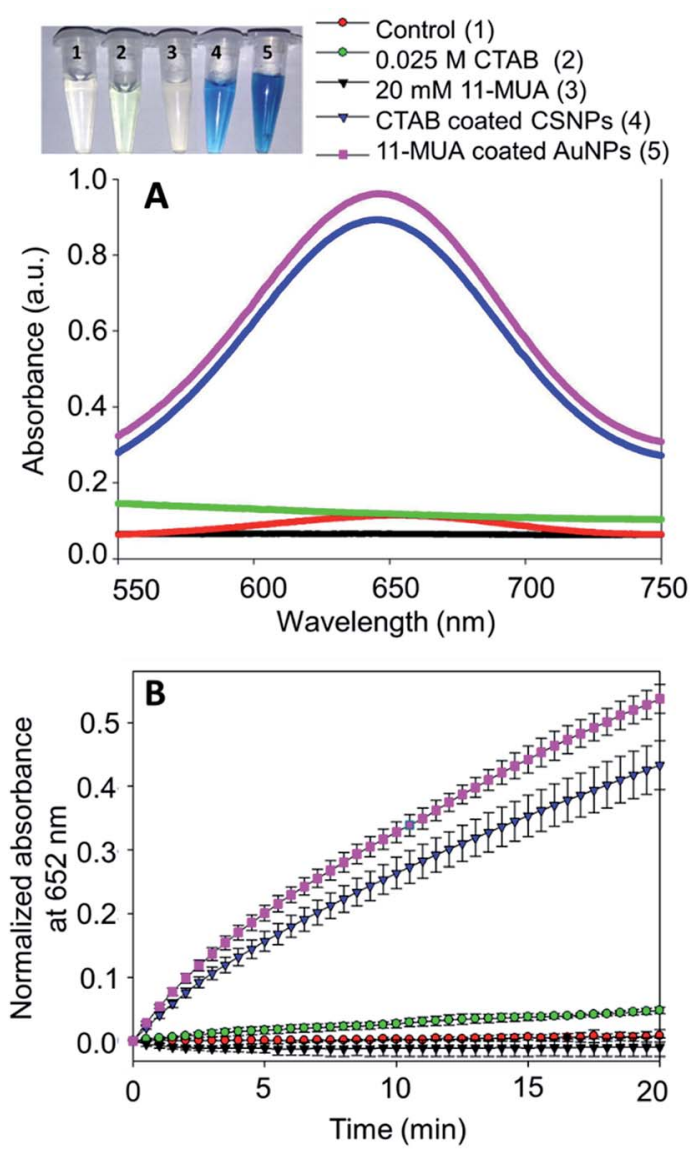

Fig. 6 Peroxidase-like activity of CSNPs: peroxidase-like activity of CTAB coated CSNPs and 11-MUA coated AuNPs was measured by following the absorbance of oxidized TMB using UV-Vis spectrophotometer (A). Inset tubes represent the color intensity of oxidized TMB in presence of NPs and $\mathrm{H}_{2} \mathrm{O}_{2}$. Tube 1, 2, 3, 4, and 5 respectively contain $\mathrm{TMB}+\mathrm{H}_{2} \mathrm{O}_{2}, 0.025 \mathrm{M}$ CTAB solution, $20 \mathrm{mM}$ 11-MUA solution, $100 \mu \mathrm{g}$ of CTAB coated CSNPs, and 11-MUA coated AuNPs. The reaction kinetics of peroxidase-like activity of CTAB coated CSNPs and 11-MUA coated AuNPs was followed by recording the change in absorbance of oxidized TMB at $652 \mathrm{~nm}$ (B). Data expressed as standard deviation calculated from 3 experiments.

shell the core AuNPs may face aggregation at higher temperature.

3.3.1.1 Kinetic parameter $\left(K_{m}\right.$ and $\left.V_{\max }\right)$ analysis. Steady-state kinetics study of TMB oxidation by CTAB coated CSNPs (Fig. 7A) and 11-MUA coated AuNPs (Fig. 7B) in presence of $\mathrm{H}_{2} \mathrm{O}_{2}$ showed a typical Michaelis-Menten equation pattern, which is evident by a hyperbolic graph plot between the substrate concentration and rate of reaction.

The kinetic parameters, $K_{\mathrm{m}}$ and $V_{\max }$, were calculated form the plotted Lineweaver-Burk plots considering the different concentrations $(0.5,1.0$, and $2.0 \mathrm{M})$ of $\mathrm{H}_{2} \mathrm{O}_{2}$ (Fig. $7 \mathrm{C}$ and D). Concerning the bi-substrate reaction, it was imperative to understand the reaction mechanism followed by NPs to exhibit peroxidase-like catalysis. The interaction of substrates with nanozyme can either be ordered sequential or random sequential reaction or Ping-Pong reaction. As clearly evident from Fig. 7C and D that the catalytic reaction of NPs (CTAB 


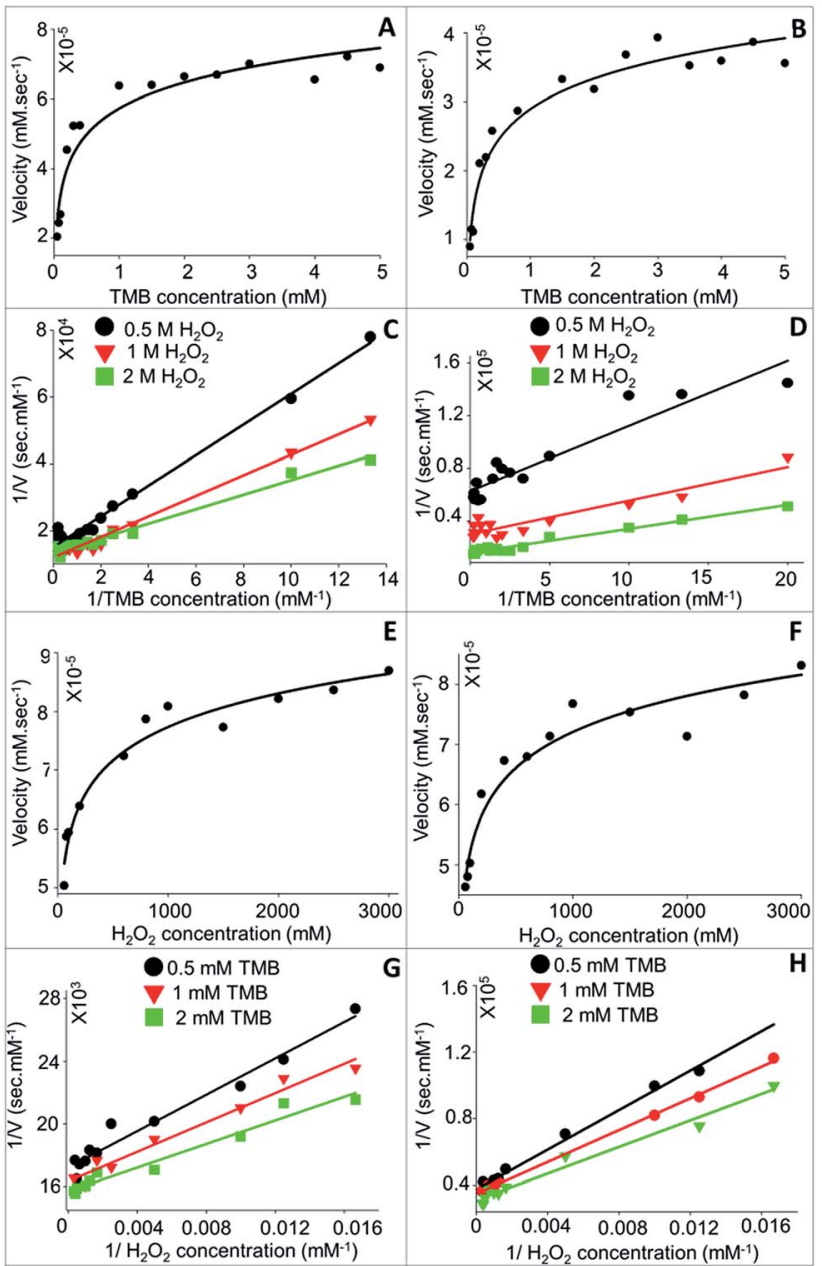

Fig. 7 Calculation of kinetic parameters $\left(K_{m}\right.$ and $\left.V_{\text {max }}\right)$ of peroxidase reaction of CSNPs: TMB dependent kinetic study for peroxidase enzyme-like activity of CTAB coated CSNPs and 11-MUA coated AuNPs. The concentration of TMB was varied from $0.05 \mathrm{mM}$ to $5 \mathrm{mM}$ while $\mathrm{H}_{2} \mathrm{O}_{2}$ concentration was constant at $2 \mathrm{M}$, with $\mathrm{CTAB}$ coated CSNPs (A) after 11-MUA coated AuNPs (B); and double reciprocal plots for CTAB coated CSNPs and 11-MUA coated AuNPs with a fixed concentration of $\mathrm{H}_{2} \mathrm{O}_{2}$ relative to varying concentration of TMB ( $\mathrm{C}$ and D). The concentration of $\mathrm{H}_{2} \mathrm{O}_{2}$ was varied from $0.5 \mathrm{M}$ to $3 \mathrm{M}$ while TMB concentration was constant at $1 \mathrm{mM}$, for CTAB coated CSNPs (E) and 11-MUA coated AuNPs (F); and double reciprocal plots for CTAB coated CSNPs and 11-MUA coated AuNPs with a fixed concentration of TMB relative to varying concentrations of $\mathrm{H}_{2} \mathrm{O}_{2}(\mathrm{G}$ and $\mathrm{H})$.

coated CSNPs - Fig. 7C and 11-MUA coated AuNPs - Fig. 7D) follow "Random $\mathrm{Bi}-\mathrm{Bi}$ " reaction mechanism because the Lineweaver-Burk plots have identical appearances and their all lines intersect to the left of the $1 / V_{\mathrm{o}}$ axis, which is a characteristic feature of "Random Sequential" mechanism. We have assumed that the peroxidase reaction shown by NPs is "Random" because the catalytic reaction does not show any significant difference by changing the sequence of addition of TMB or $\mathrm{H}_{2} \mathrm{O}_{2}$ to the reaction mixture. Interestingly, the CTAB coated CSNPs and 11-MUA coated AuNPs showed a similar pattern of Lineweaver-Burk plots, therefore, it is assumed that in both the cases the reaction mechanism is the "Random $\mathrm{Bi}-\mathrm{Bi}$ ", which was not altered even after the change in the coating. Similarly, we considered another substrate $\left(\mathrm{H}_{2} \mathrm{O}_{2}\right)$ and varied the concentrations of TMB $(0.5,1.0$, and $2.0 \mathrm{mM})$ to investigate the reaction mechanism (Fig. 7E-H). As expected, the LineweaverBurk plots showed the characteristic pattern of "Random Bi-Bi" reaction of peroxidase-like activity of CSNPs. From the kinetic analysis, the calculated values of $K_{\mathrm{m}}$ for TMB at three different $\mathrm{H}_{2} \mathrm{O}_{2}$ concentrations $0.5,1.0$, and $2.0 \mathrm{M}$ was $0.30,0.25$, and $0.16 \mathrm{mM}$, respectively for CTAB coated CSNPs (Table 2). However, for 11-MUA coated AuNPs the $K_{\mathrm{m}}$ values of TMB decreases to $0.07,0.09$, and $0.11 \mathrm{mM}$, suggesting better affinity of TMB with 11-MUA coated CSNPs. Subsequently, the $V_{\max }$ values suggest that $\mathrm{CTAB}$ coated CSNPs catalyze the reaction with the velocity of $6.6 \times 10^{-5}, 8.33 \times 10^{-5}$ and $7.44 \times 10^{-5} \mathrm{mM}$ $\mathrm{s}^{-1}$ when used 0.5, 1.0, and $2.0 \mathrm{M}$ concentration of $\mathrm{H}_{2} \mathrm{O}_{2}$, respectively. Interestingly, the $V_{\max }$ values of 11-MUA coated AuNPs catalyzed reaction was found to be $1.59 \times 10^{-5}, 3.35 \times$ $10^{-5}$, and $6.38 \times 10^{-5} \mathrm{mM} \mathrm{s}^{-1}$ for same $\mathrm{H}_{2} \mathrm{O}_{2}$ concentrations. The comparative analysis of $V_{\max }$ values suggests that the peroxidase reaction velocity was altered significantly after replacement of CTAB with 11-MUA from CSNPs surface. Subsequently, the $K_{\mathrm{m}}$ values $\left(24.39,28.64\right.$, and $34 \mathrm{mM}$ ) of $\mathrm{H}_{2} \mathrm{O}_{2}$ was also calculated at three different TMB concentrations $(0.5$, 1.0, and $2.0 \mathrm{mM}$ ), respectively when used CTAB coated CSNPs for peroxidase reaction. Whereas when 11-MUA coated AuNPs were used, the $K_{\mathrm{m}}$ values of $\mathrm{H}_{2} \mathrm{O}_{2}$ and different TMB concentrations (as above) was found to be 160.5, 173.03, and $193.15 \mathrm{mM} \mathrm{s}^{-1}$. Similarly, in the peroxidase reaction catalyzed by CTAB coated CSNPs the $V_{\max }$ values for $\mathrm{H}_{2} \mathrm{O}_{2}$ at different TMB concentrations were found to be $4.50 \times 10^{-5}, 6.11 \times 10^{-5}$, and $7.02 \times 10^{-5} \mathrm{mM} \mathrm{s}^{-1}$. However, in the peroxidase reaction catalyzed by 11-MUA, the $V_{\max }$ values for $\mathrm{H}_{2} \mathrm{O}_{2}$ at different TMB concentrations were found to be $2.67 \times 10^{-5}, 2.88 \times 10^{-5}$, and $3.21 \times 10^{-5} \mathrm{mM} \mathrm{s}^{-1}$. Thus, the $K_{\mathrm{m}}$ and $V_{\max }$ values of $\mathrm{H}_{2} \mathrm{O}_{2}$ also revealed that there was significant alteration in the kinetics of the peroxidase reaction shown by CTAB coated CSNPs and 11MUA coated AuNPs.

3.3.2 Super-oxide dismutase and catalase-like activity. Biological SOD and catalase enzymes are some of the major antioxidants involved in establishing cytoplasmic redox balance. SOD enzyme catalyzes the dismutation of superoxide anions into molecular oxygen and $\mathrm{H}_{2} \mathrm{O}_{2}$. Similarly, catalase enzyme degrades $\mathrm{H}_{2} \mathrm{O}_{2}$ into water and molecular oxygen. Considering the importance of SOD and catalase enzymes, we next investigated any potential changes in these catalytic activities of NPs after 11-MUA coating. Different concentrations $\left(50,75,100\right.$, and $\left.150 \mu \mathrm{g} \mathrm{mL}{ }^{-1}\right)$ of 11-MUA coated AuNPs were tested for SOD enzyme-like activity. As evident from the reaction kinetics (Fig. 8A), the 11-MUA coated AuNPs did not show SOD activity at any of the tested concentrations. Whereas the $100 \mu \mathrm{g}$ $\mathrm{mL}^{-1}$ of CTAB coated CSNPs (sample before 11-MUA coating) and bare $\mathrm{CeO}_{2}$ NPs showed excellent SOD activity.

The SOD activity of $\mathrm{CeO}_{2}$ NPs is reported to be associated with the oxygen vacancy and $\mathrm{Ce}^{3+}$ oxidation state of surface "Ce" atoms. Further, $\mathrm{CeO}_{2} \mathrm{NPs}$ with high $\mathrm{Ce}^{3+}$ oxidation state atoms show characteristic absorbance at $\sim 250 \mathrm{~nm} .{ }^{28}$ In our CSNPs, this absorbance is shifted towards higher wavelength (Fig. 1B) 
Table 2 Kinetic parameters $\left(K_{\mathrm{m}}\right.$ and $\left.V_{\text {max }}\right)$ for the substrate during the peroxidase-like activity shown by CTAB coated CSNPs and 11-MUA coated AuNPs

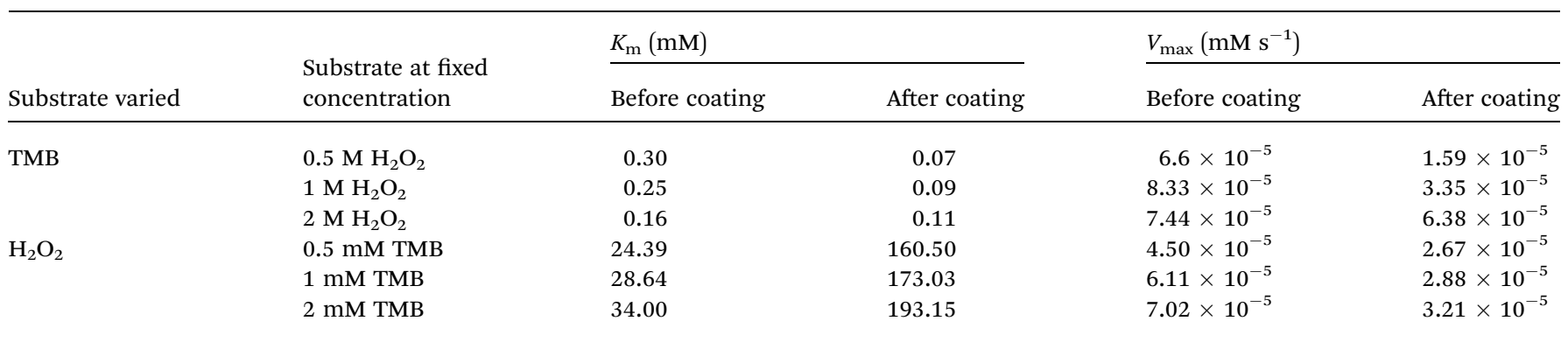

due to the formation of a shell layer over Au core. This observation suggests the loss of SOD activity on CSNPs after 11-MUA coating, which could be due to the loss of $\mathrm{CeO}_{2}$ shell layer from the surface of CSNPs. Similarly, we did not find the catalase enzyme-like activity in 11-MUA coated AuNPs (50 and $100 \mu \mathrm{g}$ $\mathrm{mL}^{-1}$ ). The 11-MUA coated AuNPs were not able to degrade the $\mathrm{H}_{2} \mathrm{O}_{2}$ and thus the absorbance at $240 \mathrm{~nm}$ remains the constant even after 20 min of incubation (Fig. 8B). However, the CTAB
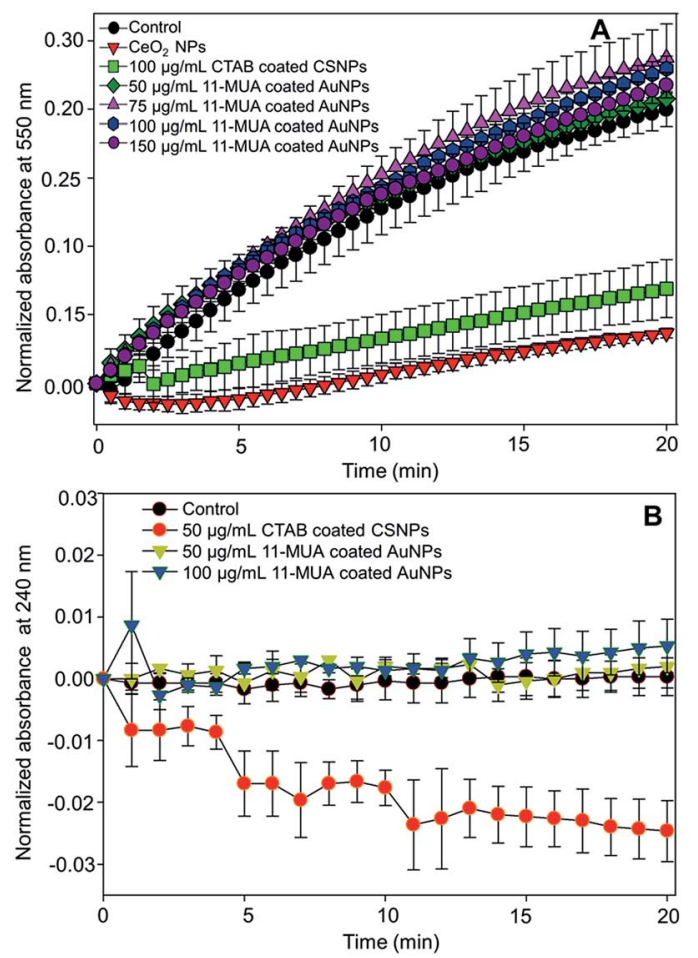

Fig. 8 SOD and catalase-like activity of CTAB coated CSNPS and 11MUA coated AuNPs: time dependent SOD-like activity of CTAB coated CSNPs $\left(100 \mu \mathrm{g} \mathrm{mL}^{-1}\right)$ and different concentration of $(50,75,100$, and $150 \mu \mathrm{g} \mathrm{mL}^{-1}$ ) of 11-MUA coated AuNPs was measured by the reduction of ferri-cytochrome $C$ by superoxide anions and measuring the absorbance at $550 \mathrm{~nm}$ (A). Time dependent catalase enzyme-like activity was measured by following the decrease in absorbance of $\mathrm{H}_{2} \mathrm{O}_{2}$ at $240 \mathrm{~nm}$ exposed to CTAB coated CSNPs $\left(50 \mu \mathrm{g} \mathrm{mL}^{-1}\right)$ and 11MUA coated AuNPs (50 and $100 \mu \mathrm{g} \mathrm{mL}^{-1}$ ) was recorded by UV-Visible spectrophotometer (B). Data expressed as standard deviation calculated from 3 experiments. coated CSNPs (50 $\left.\mu \mathrm{g} \mathrm{mL}^{-1}\right)$ displayed excellent catalase enzymelike activity, which is evident from the degradation of $\mathrm{H}_{2} \mathrm{O}_{2}$ and a concomitant decrease in absorbance at $240 \mathrm{~nm}$ (Fig. 8B, red curve). It must be emphasized here that in $\mathrm{Au}$ core $\mathrm{CeO}_{2}$ shell NPs the SOD and catalase enzyme-like activities aroused due to $\mathrm{CeO}_{2}$ shell. Specifically, the SOD enzyme-like activity was observed due to the presence of $\mathrm{Ce}(+3$ oxidation state), whereas the catalase activity was found due to the $\mathrm{Au} / \mathrm{Ce}$ redox couple formation, which results in the formation of $\mathrm{Ce}(+4$ oxidation state) at the interface of $\mathrm{Au}$ core and $\mathrm{CeO}_{2}$ shell and within the matrix. ${ }^{37}$ Therefore, due to the loss of $\mathrm{CeO}_{2}$ from the surface of AuNPs (core), we hypothesize that both of these enzyme-like activities are lost in 11-MUA coated AuNPs. We have recently shown that the SOD and catalase enzyme-like activities of $\mathrm{CeO}_{2}$ NPs can be controlled by the use of phosphate molecules. Contrary to the inhibition of SOD activity of $\mathrm{CeO}_{2} \mathrm{NPs}(+3$ oxidation state), phosphate molecules do not alter the catalase enzyme-like activity of $\mathrm{CeO}_{2}$ NPs ( +4 oxidation state).$^{45}$ Therefore, one must carefully select the molecules for surface modification of nanozymes.

\section{Conclusions}

Surface coating of $\mathrm{Au}$ core $\mathrm{CeO}_{2}$ shell NPs can be successfully achieved by 11-MUA. Due to the strong affinity of thiolcontaining 11-MUA molecules, the surface $\mathrm{CeO}_{2}$ is also removed with $\mathrm{CTAB}$. The electron microscopy images reveal the loss of $\mathrm{CeO}_{2}$ from AuNPs surface after 11-MUA coating. Low concentrations of CTAB coated CSNPs are extremely toxic to human liver cells (WRL-68), however, 11-MUA coated AuNPs showed no signs of toxicity even up to the $100 \mu \mathrm{g} \mathrm{mL} \mathrm{m}^{-1}$ concentration. We also found that CTAB coated CSNPs exposure to WRL-68 cells leads to the high levels of oxidative stress in cells, whereas the AuNPs after 11-MUA coating did not induce the cytoplasmic free radical formation. The 11-MUA coated AuNPs were not found inducing any significant change in the morphology and viability of exposed WRL-68 cells. The peroxidase enzyme-like activity of CSNPs was found unaffected after 11-MUA coating. The catalytic reaction mechanism of peroxidase-like activity of CTAB coated CSNPs was found to be the "Random Bi-Bi", which also remains unaltered after 11MUA coating on AuNPs. The other kinetic parameters, $K_{\mathrm{m}}$ and $V_{\max }$ values, of 11-MUA coated AuNPs were found to be 
comparable to the CTAB coated CSNPs. Interestingly, the SOD and catalase enzyme-like activities were lost in 11-MUA coated AuNPs, which is expected due to the loss of $\mathrm{CeO}_{2}$ layer from as shell from AuNPs (core) surface. Although the present study reports the successful replacement of CTAB from Au core $\mathrm{CeO}_{2}$ shell NPs by 11-MUA, which in turn imparts biocompatibility to the material, the loss of SOD and catalase enzyme-like activities compromise the multifunctional property of CSNPs. Therefore, a more in-depth study with better coating molecule is needed to exploit the full potential of $\mathrm{Au}$ core $\mathrm{CeO}_{2}$ shell NPs as multifunctional nanosystem and realize a variety of biological applications.

\section{Conflicts of interest}

Authors declare no conflict of interest.

\section{Acknowledgements}

The financial assistance for the Centre for Nanotechnology Research and Applications (CENTRA) by the Gujarat Institute for Chemical Technology (GICT), Gandhinagar and the funding from the Science and Engineering Research Board (SERB), India, Grant No. ILS/SERB/2015-2016/01 to Dr Sanjay Singh under the scheme of start-up research grant in Life Sciences is also acknowledged. The Early Carrier Research grant Award (ECRA) (Project No. ECR/2016/000055) is also gratefully acknowledged. Authors acknowledge the infrastructure support from the RMIT Microscopy and Microanalysis Facility (RMMF) that were used to perform HR-TEM and EDX studies on nanomaterials.

\section{References}

1 Y. Zhou, B. Liu, R. Yang and J. Liu, Bioconjugate Chem., 2017, 28, 2903-2909.

2 N. V. S. Vallabani and S. Singh, 3 Biotech, 2018, 8(279), 1-12. 3 S. Singh, Biointerphases, 2016, 11, 04B202.

4 M. N. Karim, S. R. Anderson, S. Singh, R. Ramanathan and V. Bansal, Biosens. Bioelectron., 2018, 110, 8-15.

5 S. Singh, Front. Chem., 2019, 7(46), 1-10.

6 R. Walther, A. K. Winther, A. S. Fruergaard, W. Van den Akker, L. Sorensen, S. M. Nielsen, M. T. Jarlstad Olesen, Y. Dai, H. S. Jeppesen, P. Lamagni, A. Savateev, S. L. Pedersen, C. K. Frich, C. Vigier-Carriere, N. Lock, M. Singh, V. Bansal, R. L. Meyer and A. N. Zelikin, Angew. Chem., Int. Ed. Engl., 2019, 58, 278-282.

7 J. Wu, S. Li and H. Wei, Chem. Commun., 2018, 54, 65206530.

8 M. Singh, P. Weerathunge, P. D. Liyanage, E. Mayes, R. Ramanathan and V. Bansal, Langmuir, 2017, 33, 1000610015.

9 M. N. Karim, M. Singh, P. Weerathunge, P. Bian, R. Zheng, C. Dekiwadia, T. Ahmed, S. Walia, E. Della Gaspera, S. Singh, R. Ramanathan and V. Bansal, ACS Appl. Nano Mater., 2018, 1, 1694-1704.
10 P. Weerathunge, D. Pooja, M. Singh, H. Kulhari, E. L. H. Mayes, V. Bansal and R. Ramanathan, Sens. Actuators, B, 2019, 297, 126737.

11 X.-Q. Zhang, S.-W. Gong, Y. Zhang, T. Yang, C.-Y. Wang and N. Gu, J. Mater. Chem., 2010, 20, 5110-5116.

12 Y. Jv, B. Li and R. Cao, Chem. Commun., 2010, 46, 8017-8019.

13 A. Asati, C. Kaittanis, S. Santra and J. M. Perez, Anal. Chem., 2011, 83, 2547-2553.

14 V. Baldim, F. Bedioui, N. Mignet, I. Margaill and J. F. Berret, Nanoscale, 2018, 10, 6971-6980.

15 V. Patel, M. Singh, E. L. H. Mayes, A. Martinez, V. Shutthanandan, V. Bansal, S. Singh and A. S. Karakoti, Chem. Commun., 2018, 54, 13973-13976.

16 L. Gao, J. Zhuang, L. Nie, J. Zhang, Y. Zhang, N. Gu, T. Wang, J. Feng, D. Yang, S. Perrett and X. Yan, Nat. Nanotechnol., 2007, 2, 577-583.

17 C. Korsvik, S. Patil, S. Seal and W. T. Self, Chem. Commun., 2007, 1056-1058.

18 T. Pirmohamed, J. M. Dowding, S. Singh, B. Wasserman, E. Heckert, A. S. Karakoti, J. E. King, S. Seal and W. T. Self, Chem. Commun., 2010, 46, 2736-2738.

19 A. S. Karakoti, S. Singh, A. Kumar, M. Malinska, S. V. Kuchibhatla, K. Wozniak, W. T. Self and S. Seal, J. Am. Chem. Soc., 2009, 131, 14144-14145.

20 A. Asati, S. Santra, C. Kaittanis, S. Nath and J. M. Perez, Angew. Chem., Int. Ed. Engl., 2009, 48, 2308-2312.

21 Y. Lin, J. Ren and X. Qu, Adv. Mater., 2014, 26, 4200-4217.

22 J. Shah, R. Purohit, R. Singh, A. S. Karakoti and S. Singh, J. Colloid Interface Sci., 2015, 456, 100-107.

23 J. Shah and S. Singh, 3 Biotech, 2018, 8, 67.

24 J. He, S. Unser, I. Bruzas, R. Cary, Z. Shi, R. Mehra, K. Aron and L. Sagle, Colloids Surf., B, 2018, 163, 140-145.

25 C.-P. Liu, K.-C. Chen, C.-F. Su, P.-Y. Yu and P.-W. Lee, Catalysts, 2019, 9, 517.

26 C.-W. Lien, C.-C. Huang and H.-T. Chang, Chem. Commun., 2012, 48, 7952-7954.

27 S. Wang, W. Chen, A. L. Liu, L. Hong, H. H. Deng and X. H. Lin, ChemPhysChem, 2012, 13, 1199-1204.

28 S. Singh, T. Dosani, A. S. Karakoti, A. Kumar, S. Seal and W. T. Self, Biomaterials, 2011, 32, 6745-6753.

29 A. Dhall, A. Burns, J. Dowding, S. Das, S. Seal and W. Self, Environ. Sci.: Nano, 2017, 4, 1742-1749.

30 P. Zhou, S. Jia, D. Pan, L. Wang, J. Gao, J. Lu, J. Shi, Z. Tang and H. Liu, Sci. Rep., 2015, 5, 14402.

31 Q. Wang, J. Chen, H. Zhang, W. Wu, Z. Zhang and S. Dong, Nanoscale, 2018, 10, 19140-19146.

32 N. Singh, M. Geethika, S. M. Eswarappa and G. Mugesh, Chem.-Eur. J., 2018, 24, 8393-8403.

33 W. Zhang, S. Hu, J.-J. Yin, W. He, W. Lu, M. Ma, N. Gu and Y. Zhang, J. Am. Chem. Soc., 2016, 138, 5860-5865.

34 Y. Chen, Y. Xianyu and X. Jiang, Acc. Chem. Res., 2017, 50, 310-319.

35 X. Ye, C. Zheng, J. Chen, Y. Gao and C. B. Murray, Nano Lett., 2013, 13, 765-771.

36 B. Li, T. Gu, T. Ming, J. Wang, P. Wang, J. Wang and J. C. Yu, ACS Nano, 2014, 8, 8152-8162. 
37 S. Bhagat, N. V. Srikanth Vallabani, V. Shutthanandan, M. Bowden, A. S. Karakoti and S. Singh, J. Colloid Interface Sci., 2018, 513, 831-842.

38 Z. Matharu, P. Pandey, M. K. Pandey, V. Gupta and B. D. Malhotra, Electroanalysis, 2009, 21, 1587-1596.

39 C. Wang, L. Xu, J. Xu, D. Yang, B. Liu, S. Gai, F. He and P. Yang, Dalton Trans., 2017, 46, 12147-12157.

40 G. Chen, Y. Wang, R. Xie and S. Gong, Adv. Drug Delivery Rev., 2018, 130, 58-72.
41 A. F. Moreira, C. F. Rodrigues, C. A. Reis, E. C. Costa and I. J. Correia, Microporous Mesoporous Mater., 2018, 270, 168-179.

42 J. M. Allen, J. Xu, M. Blahove, S. A. Canonico-May, T. J. Santaloci, M. E. Braselton and J. W. Stone, J. Colloid Interface Sci., 2017, 505, 1172-1176.

43 A. P. Leonov, J. Zheng, J. D. Clogston, S. T. Stern, A. K. Patri and A. Wei, ACS Nano, 2008, 2, 2481-2488.

44 J. G. Mehtala, D. Y. Zemlyanov, J. P. Max, N. Kadasala, S. Zhao and A. Wei, Langmuir, 2014, 30, 13727-13730.

45 R. Singh and S. Singh, Colloids Surf., B, 2015, 132, 78-84. 